\title{
Unusual cases of acute cholecystitis and cholangitis: Tokyo Guidelines
}

\author{
Hideki Yasuda $^{1}$, Tadahiro Takada ${ }^{2}$, Yoshifumi Kawarada ${ }^{3}$, Yuji Nimura ${ }^{4}$, Koichi Hirata 5 , \\ Yasutoshi Kimura ${ }^{5}$, Keita Wada ${ }^{2}$, Fuminiko Miura ${ }^{2}$, Masahiko Hirota ${ }^{6}$, Toshiniko Mayumi ${ }^{7}$, \\ Masahiro Yoshida ${ }^{2}$, Masato Nagino ${ }^{4}$, Yuichi Yamashita ${ }^{8}$, Serafin C. Hilvano ${ }^{9}$, and Sun-Whe Kim ${ }^{10}$ \\ ${ }^{1}$ Department of Surgery, Teikyo University Chiba Medical Center, 3426-3 Anesaki, Ichihara, Chiba 299-0111, Japan \\ ${ }^{2}$ Department of Surgery, Teikyo University School of Medicine, Tokyo, Japan \\ ${ }^{3}$ Mie University School of Medicine, Mie, Japan \\ ${ }^{4}$ Division of Surgical Oncology, Department of Surgery, Nagoya University Graduate School of Medicine, Nagoya, Japan \\ ${ }^{5}$ First Department of Surgery, Sapporo Medical University School of Medicine, Sapporo, Japan \\ ${ }^{6}$ Department of Gastroenterological Surgery, Kumamoto University Graduate School of Medical Science, Kumamoto, Japan \\ ${ }^{7}$ Department of Emergency Medicine and Critical Care, Nagoya University School of Medicine, Nagoya, Japan \\ ${ }^{8}$ Department of Surgery, Fukuoka University Hospital, Fukuoka, Japan \\ ${ }^{9}$ Department of Surgery, Philippine General Hospital, University of the Philippines, Manila, Philippines \\ ${ }^{10}$ Department of Surgery, Seoul National University College of Medicine, Seoul, Korea
}

\begin{abstract}
Unusual cases of acute cholecystitis and cholangitis include (1) pediatric biliary tract infections, (2) geriatric biliary tract infections, (3) acalculous cholecystitis, (4) acute and intrahepatic cholangitis accompanying hepatolithiasis (5) acute biliary tract infection accompanying malignant pancreatic-biliary tumor, (6) postoperative biliary tract infection, (7) acute biliary tract infection accompanying congenital biliary dilatation and pancreaticobiliary maljunction, and (8) primary sclerosing cholangitis. Pediatric biliary tract infection is characterized by great differences in causes from those of adult acute biliary tract infection, and severe cases should be immediately referred to a specialist pediatric surgical unit. Because biliary tract infection in elderly patients, who often have serious systemic conditions and complications, is likely to progress to a serious form, early surgery or biliary drainage is necessary. Acalculous cholangitis, which often occurs in patients with serious concomitant conditions, such as those in intensive care units (ICUs) and those with disturbed cardiac, pulmonary, and nephric function, has a high mortality and poor prognosis. Cholangitis accompanying hepatolithiasis includes recurrent pyogenic cholangitis, an epidemic disease in Southeast Asia. Biliary tract infections, which often occur after a biliary tract operation and treatment of the biliary tract, may have a fatal outcome, and should be carefully observed. The causes of acute cholangitis associated with pancreaticobiliary maljunction differ before and after operation. Direct cholangiography is most useful in the diagnosis of primary sclerosing cholangitis. If cholangiography visualizes a typical bile duct, differentiation from acute pyogenic cholangitis is easy. This article discusses the individual characteristics, diagnostic criteria, treatment guidelines, and prognosis of these unusual types of biliary tract infection.
\end{abstract}

Offprint requests to: $\mathrm{H}$. Yasuda

Received: May 31, 2006 / Accepted: August 6, 2006
Key words Cholangitis - Acute cholecystitis - Pediatric biliary tract infection $\cdot$ Geriatric biliary tract infection

\section{Introduction}

Unusual cases of acute cholecystitis and cholangitis include: (1) pediatric biliary tract infections, (2) geriatric biliary tract infections, (3) acalculous cholecystitis, (4) cholangitis accompanying hepatolithiasis and intrahepatic cholangitis, (5) acute biliary tract infections accompanying malignant pancreatic biliary tumor, (6) postoperative biliary tract infections, (7) acute biliary tract infections accompanying congenital biliary dilatation and pancreaticobiliary maljunction, and (8) primary sclerosing cholangitis.

This article discusses the characteristics, diagnostic criteria, treatment guidelines, and prognoses of these unusual types of biliary tract infection in a question and answer format.

\section{Pediatric biliary tract infections}

\section{Q1. What are the causes of pediatric cholangitis and cholecystitis?}

The causes of pediatric acute biliary tract infections are quite different from those of adult acute biliary tract infection.

Pediatric acute biliary tract infection is a rare disease, occurring most often in children (less than 15 years old) with specific diseases such as biliary atresia and pancre- 
aticobiliary maljunction, or after liver transplantation. Ascending cholangitis (hereinafter "cholangitis") occurs in as many as $50 \%$ of children after operation for biliary atresia, and these children should therefore be monitored carefully (level 4). The condition often occurs within a year after the operation.

Acute cholecystitis occurs very rarely $(0.13 \%-0.22 \%)$ in children as compared with the incidence in adults. According to a review of 693 cases, conducted in 1989 by Friesen and Roberts, ${ }^{1}$ the ages when pediatric cholecystitis occurs are distributed as follows: 9.8\% (1 year old or younger), $4.5 \%$ (1-5 years old), $14.5 \%$ (6-10 years old), and $71.5 \%$ (age, 11-20 years) (level 3b-4). The causes of pediatric acute cholecystitis, including hemolytic hematopathy, congenital malformations, intravenous hyperalimentation, ileectomy, and shortbowel syndrome, are different from those of adult cholecystitis (level 3b-4)., ${ }^{2,3}$ Pediatric acalculous cholecystitis has various causes, mainly serious burns and metabolic diseases, and it occurs after serious operations and bone marrow transplantation. Pediatric acalculous cholecystitis is very rare and accounts for only $2 \%-15 \%$ of all types of acute cholecystitis in children (level 4). ${ }^{4}$

Q2. What are the diagnostic criteria for pediatric acute biliary tract infection?

The diagnosis of pediatric acute cholangitis should be done in accordance with the draft diagnostic, criteria shown below. Precautions should be taken, particularly for patients after operation for biliary atresia.

For the diagnosis of pediatric acute cholecystitis, the draft diagnostic criteria shown below should be referred to.

Draft diagnostic criteria for pediatric acute cholangitis

Children after an operation for biliary atresia who have a fever of $38^{\circ} \mathrm{C}$ or higher are diagnosed as having suspected acute biliary tract infection.

Children after a biliary atresia operation or after liver transplantation who have a fever of $38^{\circ} \mathrm{C}$ or higher, and an increased white blood cell count or increased C-reactive protein, and/or increased transaminase level are definitely diagnosed having as acute cholangitis.

Those with sludge or gallstones in the bile duct observed by abdominal ultrasonography, a fever of $38^{\circ} \mathrm{C}$ or higher, an increased white blood cell count or increased $\mathrm{C}$-reactive protein, and/or increased transaminase level are definitely diagnosed as having acute cholangitis.
The majority of pediatric acute cholangitis occur in children who have undergone biliary operations for such diseases as biliary atresia and cholangiectasis, and those with liver transplantation. For children with abdominal pain and fever as the main complaints, it is essential to ask their past history of disease and surgery. If they have a history of the above diseases, the diagnosis should be performed with acute biliary tract infection in mind. The above diagnostic guidelines for pediatric cholangitis are not evidence-based, but are only draft guidelines.

Almost all patients with post-biliary atresia cholangitis have a fever of $38^{\circ} \mathrm{C}$ or over. Reduced biliary excretion volume, leukocytosis, elevated levels of Creactive protein, bilirubin in plasma, and alkaline phosphatase may be observed in some patients (level 4)..$^{5-7}$ However, fever is the only finding observed in all patients, and even fever caused by a viral infection or cold-induced dyspepsia may often cause cholangitis with dehydration or reduced systemic immunity. In view of the fact that nearly half of those patients with fever and reduced biliary excretion (gray-white stool) later show an elevated plasma level of bilirubin, it is preferable to begin early treatment for those with fever as the only symptom, with the potential of cholangitis in mind. Therefore, patients with fever after operation for biliary atresia should be suspected of having acute cholangitis, and should receive treatment similar to that for acute cholangitis. Differentiation from other frequent diseases in children, such as acute pharyngitis and acute viral enteritis (rota-virus enteritis) is important. However, if these diseases are present after biliary atresia operation or liver transplantation in children, the diagnosis becomes more difficult.

Acute cholangitis in children without a history of surgery should be diagnosed comprehensively with ultrasonographic, blood biochemical, and pathological findings, with the possibility of acute cholangitis always in mind.

Draft diagnostic criteria for pediatric acute cholecystitis

Patients with symptoms such as fever and abdominal pain and findings of cholecystitis on abdominal ultrasonography are definitely diagnosed as having acute cholecystitis.

Fever, vomiting, right hypochondrial tenderness, abdominal pain (spontaneous pain), and jaundice are important findings in the diagnosis of acute cholecystitis (level 4). ${ }^{4}$ Blood biochemical tests show elevated white blood cell counts, plasma bilirubin, alkaline phosphatase, asparatate aminotransferase, and alanine aminotransferase (level 4). ${ }^{4}$ Abdominal ultrasonography is 
useful for diagnosis in children, as well as for adults (level 3b-4), ${ }^{2,4}$

Q3. What are the appropriate criteria for primary care and patient transfer?

Primary care for pediatric acute biliary tract infection consists of: (1) fasting, (2) adequate intravenous fluid infusion, and (3) intravenous antimicrobial administration. Patients should be transferred, as required, to a specialist pediatric unit, according to the criteria below.

Primary care should be started and patients should be referred to a pediatric surgery unit if they have a history of biliary tract surgery or definitive cholangitis.

Primary care for pediatric acute biliary tract infection consists of: (1) fasting, (2) adequate intravenous fluid infusion, and (3) intravenous antimicrobial administration, and the patients should be referred or transferred, as required, to a specialist unit where treatment by pediatricians is available, according to the above criteria.

As various causative bacteria for cholangitis occurring after a biliary atresia operation, broad spectrum antimicrobial drugs are effective as their bactericidal effect on enterobacteria, which are mainly gram-negative bacilli, is high (level 4). ${ }^{8} \mathrm{~A}$ third-generation cephem antimicrobial, or in some cases, an aminoglycoside antimicrobial as well, should therefore be administered, taking the production of drug-resistant bacteria into account (level 4-5) ${ }^{6,8}$ However, treatment of the cholangitis that may occur after an operation for biliary atresia is directly associated with the prognosis of the biliary atresia, and whether or not the cholangitis is successfully controlled is associated with an indication for liver transplantation; therefore, patients should undergo the treatment at a specialist unit after undergoing primary care.

The primary care of cholecystitis consists, in principle, of fasting (aspiration of stomach contents via a nasogastric tube as appropriate), adequate intravenous fluid inffusion, and intravenous administration of appropriate antimicrobial drugs, and this should be accompanied by strict ultrasonographic follow-up (level 4).,4 As cholecystitis in infants is likely to progress to a severe form, emergency treatment may be required in some cases.

\section{Geriatric biliary tract infections}

There is no common definition of "elderly", and definitions differ by individuals, culture, and country. The World Health Organization defines the elderly as those aged 65 years and over. Geriatrically, the definition of "elderly" is subdivided into "early elderly (65 years old and older)", "medium elderly (75 and older)", and "later elderly ( 85 years and older)". The ages at which biliary tract infections occur most frequently are the sixties and seventies, and many patients with biliary tract infection are categorized as "elderly". The definition of "elderly" employed in the references and reports on geriatric biliary tract infection is diverse, but it is useful to classify geriatric biliary tract infection at the higher age for understanding and identifying morbid conditions specific to geriatric patients. The Tokyo Guidelines define biliary tract infections in those 75 years and over as "geriatric biliary tract infections".

\section{Q4. What treatment method is preferred for elderly patients?}

Biliary drainage is the treatment of choice for moderate or severe acute cholangitis in elderly patients (recommendation $\mathrm{C}$ ).

Acute cholangitis in elderly patients often progresses to a serious form or to acute obstructive suppurative cholangitis, because of its anatomical characteristics. In patients 70 years and over with jaundice, this is likely to be accompanied by bactibilia and bacteremia, and they may require hospitalizion for a long period of time. Preferably, these patients should undergo early drainage. However, in view of the fact that elderly patients often have complications, there are many opinions that the first treatment should be endoscopic biliary drainage rather than an invasive treatment. Endoscopic biliary drainage is applicable for elderly patients. Reports that the success rate of endoscopic lithotomy was $98 \%$ in 101 patients 75 years and over when endoscopic retrograde cholangiopancreatography (ERCP) was applied (level 4), ${ }^{1}$ and that ERCP was applied in 23 patients 90 years and over (level 4), ${ }^{2}$ and that the success rate of endoscopic sphincterotomy (EST) was similar in patients 80 years and over (182 cases) and younger patients (level $3 b),{ }^{3}$ encourage diagnosis and treatment with ERCP for elderly patients. One report recommends endoscopic nasobiliary drainage (ENBD) without sphincterotomy as the method of first choice in the treatment of elderly patients 80 years and over (level $3 b),{ }^{4}$ while an other report suggests percutaneous transhepatic drainage (level 4). ${ }^{5}$ Because being elderly is one of the risk factors for progression to a severe form, as described in the severity classification, even those with moderate and mild cases of acute cholangitis should be treated as a high-risk group.

\section{Q5. What are the morbid conditions in acute cholecystitis?}

It is known that acute cholecystitis occurs frequently in elderly patients, who have age-related changes of the 
biliary tract structure and a frequent incidence of bacteria in bile. As acute cholecystitis in patients over 70 years old is often complicated by acalculous cholecystitis, choledocholithiasis, gallbladder necrosis, and cancer, and is likely to be associated with bacteremia, the importance of early treatment is indicated (level $3 b){ }^{6}$ The complication of peritonitis increases in proportion to age, and the complication rate in patients in their eighties is significantly higher than that at other ages. According to Andersson et al., ${ }^{7}$ biliary peritonitis was observed in $1.8 \%$ of patients with acute cholecystitis, two-thirds of whom showed clear gallbladder perforation. On the other hand, as the three-layer structure and the thickening of the gallbladder wall, which are frequently observed on abdominal ultrasonography in acute cholecystitis patients 75 years and over, are not observed in many "later" elderly patients, the diagnosis is difficult in many of these patients.

Q6. What is the optimal treatment of acute cholecystitis in elderly patients diagnosed as inoperable due to a high surgical risk?

Percutaneous transhepatic gallbladder drainage is the treatment of choice for the elderly with acute cholecystitis who are diagnosed as inoperable due to a high surgical risk (recommendation $\mathrm{C}$ ).

Some reports (case-series studies) have examined the effectiveness and safety of percutaneous transhepatic gallbladder drainage as the treatment of first choice for acute cholecystitis in elderly patients, particularly in those with comorbid conditions, and they indicate its usefulness (level 4). ${ }^{8-10}$ The treatment of acalculous cholecystitis can be completed without cholecystectomy if the patiens' condition is successfully improved by percutaneous transhepatic gallbladder drainage (PTGBD) (level 4). ${ }^{10}$ For patients complicated by cholelith, on the other hand, cholecystectomy is recommended, ultimately, if patients are operable after the improvement of their systemic condition (level 4). ${ }^{10}$

\section{Q7. What is the optimal timing of surgical treatment for acute cholecystitis in elderly patients?}

Emergency surgery for acute cholecystitis in elderly patients (recommendation $\mathrm{C}$ ).

According to randomized controlled trials (RCTs), early surgery is desirable for acute cholecystitis (7 days after the onset). Studies on the timing of surgery for acute cholecystitis in the elderly, most of which are retrospective, have recommended both early and delayed surgery. Edlund and Liungdah $\mathrm{l}^{11}$ recommend early cholecystectomy for acute cholecystitis in the elderly 70 years and over, in view of its favorable results (level 3b). Another study reports that, because, in the elderly aged 70 years and over, cholecystectomy as emergency surgery is likely to be complicated by sepsis, resulting in a mortality as high as $10 \%$ (level 4$),{ }^{12}$ the emergency surgery should be avoided. For acute cholecystitis in the elderly aged 70 years and over, primary care to improve the systemic condition with PTGBD prior to cholecystectomy reduces the postoperative mortality and morbidity rates (level 4), ${ }^{10}$ and delayed cholecystectomy is recommended only after the disappearance of inflammation, by applying PTGBD to carefully examine and treat accompanying diseases, including choledocholithiasis (level 4).$^{13}$ In a contrasting finding, a group of patients who underwent early surgery after PTGBD showed better results than those not undergoing PTG$\mathrm{BD}$ or those undergoing delayed surgery after PTGBD: the higher the success rate of intraoperative cholangiography, the lower was the rate of conversion to open surgery and the shorter the time of operation (level 3b). ${ }^{14}$ No conclusion has been reached on the timing of surgery for acute cholecystitis in the elderly. In view of their worse systemic condition and more complications in general, including choledocholithiasis, as compared with younger patients, elderly patients should receive surgery only after careful and adequate examination of their systemic condition.

Q8. What surgical method should be applied for acute cholecystitis in the elderly?

Cholecystectomy for acute cholecystitis in the elderly (recommendation grade $\mathbf{C}$ ).

Laparoscopic cholecystectomy is desirable in all eligible patients (recommendation $\mathbf{C}$ ).

After the introduction and popularization of laparoscopic cholecystectomy, its superiority has been reported in an increasing number of studies. Laparoscopic cholecystectomy performed for acute cholecystitis in the elderly 75 years and over requires a shorter time of operation and a shorter length of hospitalization, and reduces the number of patients who need rehabilitation and the mortality rate, as compared with open cholecystectomy (level 3b). ${ }^{15}$ The mortality rate of laparoscopic cholecystectomy is the same as that of open cholecystectomy (level 4). ${ }^{16}$ The morbidity rate of open cholecystectomy is about seven times higher than that of laparoscopic cholecystectomy, and the elderly and highrisk patients in higher American Society of Anesthesiology (ASA) Physical Class System classes should undergo laparoscopic cholecystectomy (level 3b). ${ }^{17}$ Laparoscopic cholecystectomy performed in the elderly 75 years and over reduces the morbidity rate and shortens the duration of hospitalization, and thus reduces medical costs 
(level 3b). ${ }^{18}$ There is a report, in contrast, that laparoscopic cholecystectomy for elderly patients 75 years and over is not very beneficial, because many of the elderly need to undergo open cholecystectomy later and to stay in hospital for the same length of time as those with open cholecystectomy (level 3b). ${ }^{19}$ There is an opinion that laparoscopic cholecystomy is preferable, similarly to delayed surgery, for patients without complications, whereas for patients 65 years and over with complications, early conversion to open cholecystectomy or the performance of open cholecystectomy is recommended (level 3b). ${ }^{20}$

\section{Acalculous cholecystitis}

Q9. What are the points to be considered in the diagnosis of acalculous cholecystitis?

- Acalculous cholecystitis occurs often in patients with severe acute cholecystitis.

- The prognosis of acalculous cholecystitis is worse than that of ordinary acute cholecystitis.

- Acalculous cholecystitis may be relieved by biliary drainage alone in some cases.

Acalculous cholecystitis often occurs in patients in the intensive care unit (ICU) and in those with cardiopulmonary-nephrotic dysfunction. The total mortality is $15 \%$, with the post-trauma mortality as high as $27 \%$ (level 4). ${ }^{1}$

Q10. What are the incidence and prognosis of acute acalculous cholecystitis?

- Acute acalculous cholecystitis accounts for $2 \%-15 \%$ of acute cholecystitis. Common risk factors of acalculous cholecystitis are operation, serious trauma, burns, and parenteral nutrition. It is also reported that the spread of malignant tumor to the hilus of the liver, hepatic arterial infusion, diabetes, specific drugs and specific infections are associated with acalculous cholecystitis. According to reports of Japanese patients, acute acalculous cholecystitis occurs often after an abdominal operation.

Acute acalculous cholecystitis accounts for $2 \%-15 \%$ of all types of acute cholecystitis (level 4)..$^{2-5}$ Acalculous cholecystitis is likely to occur in patients with serious disease, and has a poor prognosis in general, due to the high incidence of morbidity, such as gangrenous cholecystitis and gallbladder perforation. According to Kalliafas et al., ${ }^{6}$ gangrenous changes, perforation, and abscess are observed in $63 \%, 15 \%$, and $4 \%$ of patients with acute acalculous cholecystitis, respectively, with a mortality of $41 \%$ (level 4 ). ${ }^{6}$ However, Ryu et al. ${ }^{7}$ reported that gangrenous changes and perforation were observed in $55 \%$ and $5.1 \%$ of patients with acute acalculous cholecystitis, respectively, while there were no fatal cases (level 4). A review of 33 case-series studies, including that by Kang and Williamson, ${ }^{1}$ showed a total mortality of $15 \%$ (91 of 594 patients died) while the mortality of post-trauma patients was high, at $27 \%$ (level 4). Table 1 shows risk factors for acute acalculous cholecystitis. According to a survey by Ida et al., ${ }^{8}$ of 145 medical institutions, 14654 patients subjected to operation for benign biliary disorders in the 3 years from 1979 through 1981 included 463 (3\%) with acalculous cholecystitis and $93(0.6 \%)$ with acalculous cholangitis (level 4).

\section{Q11. What are the risk factors for acute acalculous cholecystitis?}

Acute acalculous cholecystitis is likely to occur during the treatment of serious conditions such as trauma and burns, and in postoperative patients (Table 1). It is reported that the incidence of acute acalculous cholecystitis rises with the increasing number of patients with

Table 1. Factors potentially associated with acute acalculous cholecystitis (Review of Barie and Fischer ${ }^{19}$ )

\begin{tabular}{|c|c|}
\hline Risk factor & Reference nos. \\
\hline \multicolumn{2}{|l|}{ Surgery } \\
\hline Heart operation & $14,16-18$ \\
\hline Heart transplantation & $20-23$ \\
\hline Aortic aneurysm & $11-13$ \\
\hline \multicolumn{2}{|l|}{ Trauma } \\
\hline \multicolumn{2}{|l|}{ Burn } \\
\hline Diabetes & $32-34$ \\
\hline Abdominal angitis & 14,30 \\
\hline $\begin{array}{l}\text { Spreading of malignant tumor involving } \\
\text { the hepatic hilus }\end{array}$ & 27 \\
\hline $\begin{array}{l}\text { Congestive heart failure, hypotension } \\
\text { caused by hemorrhagic shock and after } \\
\text { cardiac arrest }\end{array}$ & 31 \\
\hline \multicolumn{2}{|l|}{ Iatrogenic } \\
\hline $\begin{array}{l}\text { Interleukin } 2 \text { therapy, lymphokine- } \\
\text { activated killer cell therapy }\end{array}$ & 34 \\
\hline $\begin{array}{l}\text { Percutaneous transhepatic biliary } \\
\text { drainage }\end{array}$ & 40 \\
\hline After bone marrow transplantation & 35 \\
\hline \multicolumn{2}{|l|}{ Spread of infection from other sites } \\
\hline Systemic candida infection & 36 \\
\hline Leptospirosis & 37 \\
\hline Tuberculosis & \\
\hline Salmonella infection of the bile duct & $38-39$ \\
\hline AIDS & $41-42$ \\
\hline \multicolumn{2}{|l|}{$\begin{array}{l}\text { Closure of entrahepatic bile ducts due to } \\
\text { rare cause }\end{array}$} \\
\hline \multicolumn{2}{|l|}{ Bloody bile } \\
\hline Echinococcosis cyst & \\
\hline
\end{tabular}


severe disease and increasingly complicated treatment procedures. ${ }^{9} 10$

Factors associated with postoperative acute cholecystitis Table 2 shows the incidence of postoperative acute cholecystitis after various operations. After aortic aneurysm repair, particularly ruptured aneurysm, the incidence of acute cholecystitis is high. In aortic aneurysm patients, the incidence of acute cholecystitis after the repair of non-ruptured aneurysm is around $1 \%,{ }^{11-13}$ but the incidence after the repair of a ruptured aneurysm is as high as $13.6 \%$ (level 4). ${ }^{11}$ Although the incidence of acute cholecystitis after cardiac surgery is not very high $(0.12 \%-0.94 \%),{ }^{14-18}$ surgery combining valve replacement and coronary artery bypass is considered as a risk factor for postoperative acute cholecystitis. A comparison of 30 patients with post-cardiovascular operation acute cholecystitis and 11300 who underwent the operation at the same time but showed no acute cholecystitis indicates that those subjected to surgery combining valve replacement and coronary artery bypass accounted for $23 \%(7 / 30)$ of patients with acute cholecystitis, but $11 \%(1299 / 11300 ; P=0.03)$ of those without appearance of the disease (level 3c). ${ }^{14}$ After cardiac transplantation, postoperative cholecystitis appears at higher incidences $(0.7 \%-5.7 \%){ }^{20-22}$ Postoperative cholecystitis occurs at similar frequencies in both calculous and acalculous patients. ${ }^{19}$ The incidence of postoperative acute calculous cholecystitis is the same in male and female patients, whereas acalculous cholecystitis is more likely to occur in male patients. According to a review by Inoue and Mishima ${ }^{23}$ of 494 postoperative acute cholecystitis patients at 122 institutions over 10 years from 1976 until 1985, the incidence of postoperative acute cholecystitis was $0.06 \%$. Of the 494 postoperative acute cholecystitis patients, 445 cases were acalculous (90\%) (level 4) and occurred at an average age of 60 years. Postoperative acute cholecystitis occurs more frequently in male patients ( 2.8 times more than in female patients) after abdominal operations (435 cases) and most frequently after gastrectomy (level 4).

\section{Post-trauma and burns}

Acute acalculous cholecystitis is likely to occur after trauma or burns. According to Kang and Williamson, ${ }^{1}$ $12 \%-49 \%$ of acute acalculous cholecystitis occurs after trauma or after critical surgery (level 4 ). The incidence of post-trauma acute cholecystitis is $3.7 \%$ in those with spinal cord injury (7 of 191 cases; acalculous cholecystitis only) and $18 \%$ in those with multiple injuries ( 8 of 45 cases; both acalculous and calculous) (level 4). ${ }^{24}$ According to Raunest et al., ${ }^{24} 90 \%$ of post-trauma acute cholecystitis in patients who underwent intensive care of multiple injuries was acalculous. Because trauma patients are mostly young males, it can be said that posttrauma acute cholecystitis occurs mostly in males.

\section{Parenteral nutrition}

Long-term parenteral nutrition causes cholestasis. Gallstones are observed in a high percentage of those subjected to parenteral nutrition for over 3 months. According to a study by Pitt et al. ${ }^{25}$ observing 71 patients undergoing parenteral nutrition for 3 months and over, $11(15 \%)$ patients had cholecystolithiasis prior to the start of nutrition and $21(35 \%)$ of the remaining 60 patients were found to have cholecystolithiasis during parenteral nutrition (level4). Patients undergoing long-term parenteral nutrition show a higher incidence of not only calculous but also acalculous cholecystitis. According to Peterson and Sheldon, ${ }^{26}$ acute acalculous cholecystitis was observed in $4 \%$ of patients undergoing central parenteral nutrition (level 4).

Table 2. Incidence of postoperative acute cholecystitis

\begin{tabular}{|c|c|c|c|c|}
\hline Author & Year of report & Characteristics & No. of cases & Incidence $(\%)$ \\
\hline Ouriel $^{12}$ & 1984 & Aneurysm repair & 703 & 1.1 \\
\hline \multirow[t]{2}{*}{ Scher ${ }^{11}$} & 1986 & Aortic aneurysm repair, elective & 352 & 1.0 \\
\hline & & Aortic aneurysm repair, emergency & 22 & 13.6 \\
\hline Hagino $^{13}$ & 1997 & Aortic aneurysm repair & 996 & 1.0 \\
\hline Barie $^{15}$ & 1993 & Cardiac surgery & 31710 & 0.12 \\
\hline Sessions $^{16}$ & 1993 & Cardiac surgery & 6393 & 0.34 \\
\hline Leitman $^{14}$ & 1987 & Cardiac surgery & 6452 & 0.94 \\
\hline Savino $^{17}$ & 1985 & Cardiac surgery & 2100 & 0.24 \\
\hline Welling 18 & 1986 & Cardiac surgery & 1596 & \\
\hline Steed $^{20}$ & 1985 & Cardiac transplantation & 142 & 0.7 \\
\hline Merrell $^{21}$ & 1989 & Cardiac transplantation & 178 & 2.2 \\
\hline Rakhit $^{22}$ & 2002 & Pediatric cardiac transplantation & 105 & 5.7 \\
\hline Takahashi ${ }^{43}$ & 1990 & Gastrectomy & 1096 & 0.6 \\
\hline Saito $^{44}$ & 1997 & Cardiac surgery ${ }^{\mathrm{a}}$ & 1015 & 0.6 \\
\hline Ishikawa $^{45}$ & 1997 & Cardiovascular surgery & 321 & 1.2 \\
\hline
\end{tabular}

Note: Prepared mainly based on the review by Barie and Fischer, ${ }^{19}$ including acalculous cholecystitis

${ }^{a}$ Study included only acalculous acute cholecystitis 


\section{Malignant tumor}

Gastric cancer, and tumors of the liver, biliary tract, and pancreas, as well as melanoma and breast cancer, if they spread to obstruct the cystic duct, may cause acute calculous cholecystitis (level 4). ${ }^{27}$

\section{Hepatic artery infusion}

Hepatic artery infusion may be associated with drug toxicity and catheter complications. According to an examination by Barnett and Malafa ${ }^{28}$ of complications in 3991 patients subjected to hepatic artery infusion, and the study of Lafon et al. ${ }^{29}$ the incidence of biliary complications, including acute cholecystitis, was $4 \%$ (level 4).

\section{Other factors}

Other factors associated with the occurrence of biliary and other types of acute acalculous cholecystitis include abdominal vasculitis, ${ }^{30}$ hemorrhagic shock, and cardiac arrest $^{31}$ (level 4 for all cases).

With respect to a correlation between diabetes and acute cholecystitis, a report indicates that the incidence of infectious complications in acute cholecystitis is increased in diabetics (level 3b), ${ }^{32}$ while on other report indicates that diabetes does not increase the risk of cholecystectomy in those with acute cholecystitis (level 2c). ${ }^{33}$

Acute acalculous cholecystitis has been observed in patients who have undergone interleukin-2 and lymphokine-activated killer cell therapy ${ }^{35}$ and bone marrow transplantation. ${ }^{35}$

Acute acalculous cholecystitis may occur as a secondary gallbladder infection following systemic candidiasis or leptospirosis, ${ }^{36-37}$ or it may occur with Salmonella typhi as causative bacteria ${ }^{38,39}$ (level 4 for references 36-39).

An examination of acalculous cholecystitis in patients with cerebral vascular disorder in the acute stage showed an incidence of acalculous cholecystitis of $1 \%$, which is almost equal to the post-trauma and postoperative incidence.

\section{Q12. What is the best method for the diagnosis of acute acalculous cholecystitis?}

\section{Abdominal echo and computed tomography (CT) are useful in the diagnosis of acute acalculous cho- lecystitis, but care should be taken, as the diagnos- tic accuracy is lower than that in calculous cholecystitis.}

Acute acalculous cholecystitis is likely to occur postoperatively and during the treatment of serious injuries and burns, and accounts for $2 \%-15 \%$ of all acute cholecystitis cases. The diagnosis is difficult, and, in Japan, the diagnostic accuracy of postoperative cholecystitis at onset is low, at only $63 \% .{ }^{46}$
As many patients with acalculous cholecystitis are in ICUs (with extubation) due to complications, clinical signs highly specific for calculous acute cholecystitis, such as sonographic Murphy's sign, are often useless in these, acalculous, patients. Cholescintigraphy is very sensitive, but is less specific, with a high false-positive rate, in disease resulting from total parenteral nutrition, fasting, or liver failure. On abdominal ultrasonography and CT, (1) thickened gallbladder wall, (2) pericholecystic fluid, and (3) subserous edema are useful signs for diagnosis. But their specificity is lower than that in calculous cholecystitis. ${ }^{47,48}$ Therefore, for infectious diseases which occur during the treatment of severe disease with an unknown cause, the possibility of acalculous cholecystitis should always be kept in mind. If the possibility of acalculous cholecystitis cannot be denied because of the absence of a focus of infection, percutaneous biliary drainage should be performed, for both microbial inspection and treatment. However, antimicrobial drugs have usually been administered to most of the patients, the positive rate of biliary culture is not high $(33 \%)\left(\right.$ level 4). ${ }^{48,49}$ Table 3 lists findings for the accuracy of diagnostic imaging in acalenlous acute cholecystitis.

\section{Q13. Can ultrasonography diagnose acalculous cholecystitis?}

The diagnosis of acalculous cholecystitis is not easy, because it is difficult to collect information on abdominal pain and Murphy's sign in patients who have disease often associated with disturbance of consciousness that is or with treatment already received for other purposes. ${ }^{50}$

Jeffrey and Sommer ${ }^{51}$ examined 14 patients with clinically suspected acalculous cholecystitis, and reported that the possibility of acalculous cholecystitis was high if the thickness of the gallbladder wall at the first examination was normal ( $3 \mathrm{~mm}$ or less) but had increased to $4 \mathrm{~mm}$ or more at the second examination within in $24 \mathrm{~h}$ (4 out of 4 cases). If the second inspection revealed that the thickness remained the same or had improved in patients with an abnormally thickened gallbladder wall at the first inspection, the incidence of acalculous cholecystitis was low (1 of 6 cases)(level 4$)$. Helbich et al., ${ }^{52}$ who performed ultrasonography in 21 ICU patients weekly, indicated that when 2 points were allotted to an enlarged gallbladder (long axis diameter, $8 \mathrm{~cm}$ or more; short axis diameter, $5 \mathrm{~cm}$ or more), thickened gallbladder wall ( $4 \mathrm{~mm}$ or more), and an image of debris, and 1 point to a striated intra-wall structure and fluid collection localized to the pericholecystic area, the incidence of acalculous cholecystitis was zero in patients with 5 points or less but high in those with 6 points or more (level 4). 
Table 3. Diagnostic imaging accuracy for acalculous acute cholecystitis

\begin{tabular}{|c|c|c|c|c|c|}
\hline \multirow[b]{2}{*}{ Author } & \multicolumn{2}{|c|}{ Abdominal ultrasonography } & \multirow{2}{*}{$\frac{\text { Abdominal CT }}{\text { Sensitivity }}$} & \multicolumn{2}{|c|}{ Cholescintigraphy } \\
\hline & Sensitivity & Specificity & & Sensitivity & False positive \\
\hline Blankenberg & $23 \%(3 / 13)$ & & & & \\
\hline Savoca & $28 \%(5 / 18)$ & & & & \\
\hline Swayne & $58 \%(7 / 12)$ & & & $91 \%$ & \\
\hline Mirvis & $92 \%(13 / 14)$ & $96 \%$ & $86 \%(6 / 7)$ & $97 \%(18 / 19)$ & $54 \%(13 / 24)$ \\
\hline Kang & $36 \%-89 \%$ & & & $83 \%-100 \%$ & \\
\hline
\end{tabular}

Review by $\mathrm{Babb}^{48}$

Absence of figures for numbers of cases means absence of the number in the original references cited in this Table

In view of these reports indicating difficulty with the initial ultrasonographic diagnosis of acalculous cholecystitis, it is important to re-examine patients suspected of having acalculous cholecystitis.

\section{Q14. What is the treatment policy for acalculous cholecystitis?}

In principle, the treatment policy for acalculous cholecystitis is the same as that for calculous cholecystitis, but the treatment method is chosen by keeping the patients systemic condition in mind.

Basic primary care must be performed before the diagnosis is established. As acalculous cholecystitis is unlikely to respond to conservative treatment and is often complicated by gangrene (with or without perforation), early cholecystectomy seems to be desirable (level 4). ${ }^{53-55}$ Recently, noninvasive PTGBD has been employed for acalculous cholecystitis, which is often observed in postoperative and post-trauma patients who are regarded as inoperable. There have been no RCTs which compared PTGBD and cholecystectomy, and the comparison in a retrospective study (level 5) ${ }^{55}$ was unreliable because PTGBD was performed in patients who were inoperable. Some reports examining PTGBD performed for elderly patients or those in poor systemic condition indicate that PTGBD, which leads to a low incidence of recrudescence could replace surgery (recommendation grade B, level 4-5). ${ }^{48,49,56}$

\section{Acute and intrahepatic cholangitis associated with intrahepatic stones}

Q15. How is hepatolithiasis diagnosed as a primary disease associated with acute cholangitis?

Patients who have symptoms of cholangitis and show localized enlargement or stenosis of an intrahepatic bile duct branch, by ultranosonography and/or CT, are suspected of having hepatolithiasis. For a definite diagnosis, the presence of stones should be confirmed by direct cholangiography, and bile culture and cytodiagnosis should be performed (recommendation $\mathbf{C}$ ).

What is hepatolithiasis?

Hepatolithiasis is a condition in which stones are present in the hepatic and/or intrahepatic bile duct. Seventy to eighty percent of cases of hepatolithiasis are of unknown cause. In countries in Asia, the incidence of hepatolithiasis differs depending on the country; thus, environmental factors are considered to be involved in the onset. ${ }^{1}$ Causes can be identified for the hepatolithiasis that occurs secondary to surgery and is associated with biliary dysplasia. Specific disorders include Oriental cholangiohepatitis, known as recurrent pyogenic cholangitis, an epidemic disease in Southeast Asia.

\section{Epidemiology and etiology of hepatolithiasis}

According to a study by Uchiyama and Tanimura, ${ }^{2}$ acute cholangitis was observed in $8.5 \%$ of 1708 patients with hepatolithiasis. Cholelithiasis consists of bilirubincalcium stones in $74.8 \%$ of patients and cholesterol stones in $13.1 \%$, but the etiology of this disease is unknown. However, in view of the fact that hepatolithiasis is not observed in western countries (although it has been reported that Escherichia coli is involved in choleithiasis), biliary tract infection is very unlikely to be a single cause of hepatolithiasis. There is a report suggesting the involvement of parasites and malnutrition. ${ }^{3}$ Clonorchiosis is asymptomatic when the count of Clonorchis sinensis remains low; however, when the count increases to 500-1000 pieces, disorders such as closure of the bile duct, suppurative cholangitis, and hepatolithiasis may occur. In the diagnosis of this disease, the presence of eggs in feces or bile, and eosinophilia on blood tests, are important findings. A survey conducted by Sasaki et al. ${ }^{4}$ in 1998 in the Goto region, Nagasaki Prefecture, known as a region epidemic for hepatolithiasis in Japan, showed that HLA antigen positivity (A26, B44, BW54, CW7, DR6) was a parameter for a high risk of hepatolithiasis. It is also known that the formation of mucin protein on the bile duct epithelium plays an important role in the formation of stones. ${ }^{4}$ 


\section{Prognosis of hepatolithiasis}

Furukawa et al., ${ }^{5}$ who observed the long term progress of acalculous hepatolithiasis, reported that symptoms ultimately appeared in 14 (11.5\%) of 122 patients. Until the development and popularization of cholangiographic lithotomy, hepatolithiasis often progressed via biliary cirrhosis, to hepatic failure because of the repeated occurrence of cholangitis. Hepatolithiasis may be complicated by biliary cancer. The incidence of complication by biliary cancer differs in different reports, but ranges from $2.4 \%$ to $17.1 \% .^{6-8}$ As stones and cancer are almost always present on the same side, repeated cholangitis or cholestasis may be one of the causes of the cancer. ${ }^{6,9}$

\section{Diagnosis of hepatolithiasis}

Hepatolithiasis is diagnosed by the presence of stones in the intrahepatic bile duct, confirmed by direct cholangiography. Charcot's triad (abdominal pain, fever, and jaundice) is observed in about $60 \%$ of the patients. ${ }^{10}$ In severe cases associated with shock and disturbed consciousness, patients may have a reduced platelet count and disseminated intravascular coagulation (DIC). Characteristic histological findings in the liver include the growth of cholangioles and inflammatory cellular infiltration in the periportal area.

Blood tests. In general, an increased white blood cell count, a high level of hepatobiliary enzymes, and hyperbilirubinemia are observed, with hyperamylasemia in $20 \%$ of patients.

Microbial examination. The rate of detection of bacteria in bile is $85 \%$, with gram-negatives such as E. coli, Klebsiella spp. and Enterobacter spp. as major causative bacteria. Enterococcus spp and Pseudomonas aeruginosa have been increasingly detected recently. ${ }^{2}$

\section{Diagnostic imaging}

Ultrasonographic diagnosis

A marked dilated extrahepatic bile duct, the presence of stones, increased echogenicity in the regional intrahepatic portal area, and localized enlargement or stricture of intrahepatic segmental bile duct branches are observed. However, there is a pitfall with ultrasonography in that an enlarged bile duct may not be visualized if it is filled with high-luminance sludge (level 4). ${ }^{11}$

\section{CT diagnosis}

CT diagnosis reveals an enlarged intrahepatic bile duct and zonal atrophy of the liver. Splenomegaly may be observed in patients with serious liver disorder. ${ }^{12}$ If the bile duct is filled with clay stones as a mold, cholelith may not be diagnosed. If there is pneumobilia due to previous treatment, CT is more useful than ultrasonography.

\section{Cholangiography}

Enlargement of the bile duct and stones are observed, though enlargement of the intrahepatic bile duct is less than that of the extrahepatic bile duct. Cholangiography shows findings such as straightening, rigidity, decreased arborization, increased branching angle, acute peripheral tapering, and multiple focal strictures of the bile duct (level 4). ${ }^{13}$

\section{Acute biliary tract infection associated with malignant pancreatic-biliary tumor}

Acute cholangitis

Q16. What is the principle of medical treatment for acute cholangitis associated with malignant biliary tumor?

Severity assessment should be performed upon the initiation of medical treatment.

The examination should be done quickly to identify the feasibility of resection. Biliary drainage should be performed in a timely manner.

Malignant pancreatic-biliary tumor sometimes develops in patients with acute cholangitis, and emergency biliary drainage is then required. The acute cholangitis observed in these patients occurs in those patients in whom (1) endoscopic retrograde cholangiopancreatography (ERCP) has been performed only for diagnostic purposes, but not for biliary drainage, and (2) those in whom biliary drainage has been performed, but, due to troubles such as catheter obstruction, an undrained area still remains. No matter how severe the acute cholangitis is, either drainage or replacement of the catheter is required depending on the cause.

When malignant pancreatic-biliary tumor is associated with acute cholangitis, an appropriate drainage method should be selected according to the site of the causative stricture or obstruction (see Q17).

\section{Q17. Which drainage method should be applied for acute cholangitis associated with pancreatic-biliary malignancies?}

For patients in whom an occlusion in the hepatic hilus and bile duct extends upstream, percutaneous transhepatic drainage should be the method of first choice, in principle, in view of the concern that endoscopic drainage may reduce the accuracy of diagnosis of upstream cancer metastases and induce cholangitis in the area of poor drainage. However, there are no RCTs comparing these two drainage methods, and the choice has been only empirical. 
- Occlusion in the hilus of liver or upstream: perform percutaneous transhepatic biliary drainage (recommendation $\mathbf{C}$ ).

- Occlusion in the middle and lower part of the bile duct: perform either endoscopic or percutaneous transhepatic biliary drainage, depending on the individual's symptoms and according to the institutions' practice (recommendation C).

There are no reports that compare endoscopic nasobiliary drainage (ENBD, or biliary tube stent placement) and percutaneous transhepatic biliary drainage in patients with occlusion in the middle and lower bile duct. However, at the institutions where staff are skillful with endoscopic examinations the tendency is to use ENBD without EST as the method of first choice, while at the institutions where staff cannot perform ENBD, percutaneous transhepatic biliary drainage is chosen. However, as it is often difficult to visualize the biliary tract clearly when endoscopic drainage is performed, percutaneous transhepatic biliary drainage is desirable.

It has been reported that the total morbidity and mortality rates after pancreaticoduodenectomy in patients who had occlusion in the middle and lower bile duct and received stenting (stent material not specified), were not different from those without stenting, but there was a significantly higher incidence of pancreatic fluid leakage in those with stenting (level 4). ${ }^{1}$ Postoperative fistula recurrence has been reported after percutaneous transhepatic biliary drainage employed for patients with biliary tract carcinoma (level 4). ${ }^{2}$

\section{Acute cholecystitis}

Q18. What is the primary care policy for acute cholecystitis complicated by gallbladder cancer?

Severity assessment should be performed simultaneously with primary care. Preoperative examination should be done as early as possible so that a one-stage radical procedure can be performed whenever possible.

Postoperative biliary drainage, which has a risk of recurrence of drainage fistula and carcinomatous peritonitis, should be avoided whenever possible.

The prognosis of gallbladder cancer complicated by acute cholecystitis depends on the degree of progress of the cancer itself, but most of these patients have a poor prognosis. Preoperative diagnosis is difficult when gallbladder cancer is complicated by acute cholecystitis, and a patient often has surgery after being diagnosed with acute cholecystitis, and gallbladder cancer is diagnosed intra- or postoperatively. In patients diagnosed postoperatively with gallbladder cancer, two-stage radical surgery is indicated if the cancer is categorized as in the proper muscular layer or deeper. However, it is extremely difficult to choose the optimal surgical method, based on an assessment of the development of morbidity, in patients with cancer associated with extremely severe inflammation. A diagnosis of gallbladder cancer after laparoscopic cholecystectomy is a risk factor for carcinomatous peritonitis and port-site recurrence. Therefore, for patients with acute cholecystitis associated with or suspected to be associated with gallbladder cancer, as soon as primary care is initiated, a preoperative examination should be conducted to enable a onestage radical operation whenever possible.

Biliary cytodiagnosis (rinsing cytodiagnosis and, aspiration cytodiagnosis) with PTGBD is useful for the diagnosis of gallbladder cancer. However, the drainage tubes used in PTGBD have interfered with diagnostic imaging or have induced recurrence of cancer at the drainage fistula in some patients. Therefore, it must be noted that biliary drainage for acute cholecystitis in patients with or suspected of having gallbladder cancer entails a risk of cancer recurrence at the drainage fistula, and a risk of carcinomatous peritonitis.

Q19. What is the treatment policy when acute cholecystitis occurs during the surgical treatment of gallbladder cancer?

During the preoperative treatment of gallbladder cancer, the cystic duct may be obstructed due to the progress of cancer and/or bile duct stenting, and acute cholecystitis may occur. In such a case, PTGBD should be performed immediately.

Biliary tract infections in patients with previous biliary-tract surgery

Q20. Is biliary tract infection hidden in postoperative patients?

Patients who have undergone surgery of the biliary tract and the upper abdomen and liver and biliary tract treatment should be observed carefully, as cholecystitis and cholangitis may be hidden. Fever may occur postoperatively, resulting from various causes, but the potential association of the fever with cholangitis should be borne in mind.

Cholangitis in patients with a history of biliary surgery

Cholangitis in patients with a history of EST and/or endoscopic papillary balloon dilatation (EPBD)

As patients with calculous cholangitis often undergo cholecystectomy before or after cholelithotomy, there 
are not many reports of long-term observations of patients with gallstones after EPBD, without a surgical operation. According to an RCT comparing EST and EPBD, the incidence of cholecystitis post-EPBD was significantly lower than that post-EST $(9.9 \%$ and $1.3 \%$ after EST and EPBD, respectively) (level 4). ${ }^{1}$ This is because the function of Vater's papilla is kept intact by EPBD, whereas EST causes retroinfection. However, in light of the possibility gallstones remaining after EPBD and the incidence of conversion to EST in symptomatic cholelithiasis patients, more cases should be collected in order to identify whether or not cholecystectomy should be performed for post-EPBD cholecystolithiasis.

\section{Cholangitis in patients with a history of surgical sphincteroplasty}

Sphincteroplasty is rarely performed currently because of the wide spread use of EST. The incidence of cholangitis in patients with sphincteroplasty is about $5.9 \%$ (level 4). ${ }^{2}$

\section{Cholangitis in patients with a history of an end-to-side} choledochojejunostomy

It is reported that postoperative cholangitis occurs in $9.2 \%-33 \%$ of patients who have had a pancreaticoduodenectomy, while $1.1 \%$ of patients who have biliary surgery need re-surgery. In general, cholangitis is caused by the disturbed and retrograde (ascending) flow of bile, due to stricture at the site of the choledochojejunostomy.

Stenosis at the site of a choledochojejunostomy. Stenosis at the site of a choledochojejunostomy was observed in $7 \%-23 \%$ of those who underwent cholangiojejunostomy (level 4), ${ }^{3,4}$ and it is a frequent cause of postoperative cholangitis. The incidence of stenos is higher if malignant tumor-induced stenosis is included.

Afferent loop syndrome. Afferent loop syndrome, induced by the occlusion of an afferent loop arising from various causes, may progress to a serious form, so these patients should be observed carefully. Afferent loop syndrome used to be confirmed by dilation of the afferent loop and its stricture on the anal side, shown by direct gastrography or diagnosed by ultrasonography and/or CT. However, for patients with a crucial stricture, direct gastrography is not applicable and magnetic resonance (MR) cholangiopancreatography (MRCP) is useful (level 4). ${ }^{4}$

Retrograde cholangitis and other forms of cholangitis. Patients with fever or abdominal pain and increased levels of biliary enzymes, such as aspartate aminotransferase and alanine aminotransferase, and an elevated inflammatory reaction after treatment or surgery of the biliary tract, are often diagnosed as having retrograde cholangitis. Pneumobilia and a contrast effect of the bile duct wall on CT may be used as supplementary proof in the diagnosis, but there are neither specific signs nor specific examination findings. Retrograde cholangitis occurs often after treatment or surgery, and is not diagnosed, or is missed, in many patients. The absence of clear diagnostic criteria for retrograde cholangitis complicates this issue.

\section{Side-to-side choledochojejunostomy}

In addition to the problems described above, precautions should be takent to prevent cholangitis (sump syndrome) that may be caused by food and sludge collecting in the remaining lower bile duct when side-to-side choledochojejunostomy. ${ }^{5}$

\section{End-to-side choledochoduodenostomy}

According to an RCT, there is no significant difference in perioperative mortality, the total incidence of morbidity, or the incidence of postoperative cholangitis between patients who have had a choledochoduodenostomy and those who have had a choledochojejunostomy (level 4). ${ }^{6}$

Side-to-side choledochoduodenostomy

Precautions should be taken, because this method causes sump syndrome.

Cholangitis and cholecystitis after operations other than those on the biliary tract

The incidence of postoperative cholecystitis after surgery other than that on the biliary tract ranges widely, from $0.1 \%-13 \%$, depending on the primary disease and surgical method. Patients should be carefully observed in view of the high incidence of acalculous cholecystitis.

It has been reported that transcatheter arterial embolization (TAE), radiofrequency ablation (RFA), and cryosurgery are followed by the occurrence of cholangitis or cholecystitis. ${ }^{7,8}$ It is difficult to identify whether these conditions are direct complications of these procedures. There is a report that intraperitoneal infectious diseases (hepatic abscess, intraperitoneal abscess, and infection from an inserted device) were observed in 12 of 158 patients who underwent cryosurgery, with 2 of the 12 patients having cholangitis (level 4). ${ }^{8}$

Post-gastrectomy acute cholecystitis, which is caused by intracystic cholestasis (under the influence of reduced gallbladder contraction caused by incision of the vagus nerve due to lymphadenectomy), disturbed blood flow in the gallbladder wall, and bacterial infection, occurred in 24 of 190 patients with gastric cancer (12.6\%). 
Particularly after Appleby surgery, the disease occurred frequently, in 10 of 37 patients. ${ }^{9}$

Acute biliary tract infections associated with congenital biliary dilatation and pancreaticobiliary maljunction

\section{Q21. What is the characteristic etiology of acute cholangitis associated with congenital biliary dilatation?}

The etiology of acute cholangitis associated with congenital biliary dilatation differs according to whether it occurs pre- or postoperatively (level 4).

Acute cholangitis associated with congenital biliary dilatation is roughly divided into two types: cholangitis as a primary symptom of congenital biliary dilatation and postoperative cholangitis.

The incidence of acute cholangitis is $9.2 \%-23.4 \%$ in patients with congenital biliary dilatation without choledocholithiasis, with the complication of acute pancreatitis in many cases (level 4). ${ }^{1,2}$ Mechanisms of the onset of cholangitis include the backflow of pancreatic fluid into the bile duct and the incarceration of a gallstone protein plug in the papilla (level 4). ${ }^{3}$ Symptoms include abdominal pain, vomiting, jaundice, and fever. Abdominal pain is observed in over $80 \%$ of infant patients 1 year and older. In patients under 1 year old, who very rarely have abdominal pain as the main complaint, vomiting, fever, and jaundice are important proofs of the diagnosis (level 4). ${ }^{4}$

Postoperative acute cholangitis occurs in $8 \%-30 \%$ of patients who undergo an operation for congenital biliary dilatation. Postoperative cholangitis and hepatolithiasis are considered to be caused by stricture at the site of a choledochoenterostomy and congenital stricture of the intrahepatic bile duct (level 4). ${ }^{5}$

\section{Because of the high morbidity of postoperative cholangitis, various methods are used at the initial operation for congenital biliary dilatation (level 4).}

To prevent postoperative cholangitis, the recommended methods are to cut and open the right and left hepatic ducts during surgery, to make a large anastomotic opening and to form a passage for the strictured intrahepatic bile duct.

\section{Primary sclerosing cholangitis (PSC)}

Q22. How do we differentiate acute cholangitis from PSC?

Direct cholangiography is most useful in the diagnosis of PSC, and acute pyogenic cholangitis can be differentiated easily if a typical cholangiograph is observed. If patients with PSC have a fever, complication by bacterial cholangitis should be borne in mind.

Primary sclerosing cholangitis (PSC) is a chronic inflammatory disease with stricture of the bile duct caused by progressive and nonspecific inflammation of the walls of the intra- and extrahepatic bile ducts. It is considered that autoimmunity is involved in the onset of PSC. The stricture and obstruction of the bile duct may cause obstructive jaundice, followed ultimately by secondary biliary cirrhosis of the liver and liver failure.

The etiology of PSC has not been identified. A report indicates the involvement of HLA DR3 and DR2 in its onset, while there are other reports that bacterial and viral infections (associated with immunodeficiency), occlusion of the hepatic artery, and disorders induced by chemotherapy are involved in the etiology.

Takikawa et al. ${ }^{1}$ reviewed 388 PSC patients in 2003 to examine the incidence and prognosis of the disease. According to their report, the age distribution of PSC patients in Japan has two peaks, one in the twenties and the other in the fifties to sixties. Younger patients are often complicated by inflammatory enteropathy, while the elderly patients are often complicated by autoimmune pancreatitis. It was also reported that the rates of complication with ulcerative colitis, autoimmune pancreatitis, cholelith, and biliary cancer were $37 \%, 7.2 \%$, $16 \%$, and $4.3 \%$, respectively. ${ }^{1}$

The clinical symptoms of PSC include jaundice (44\%), systemic itchiness $(27 \%)$, abdominal pain $(18 \%)$, fever $(10 \%)$, and systemic weariness (4\%). PSC may be complicated by retrograde bacterial cholangitis as a longterm outcome. ${ }^{2}$ There are no studies that have confirmed bacterial cholangitis by examining for the presence of bacteria in bile while the patient has a fever, and it is not certain whether a fever directly represents the complication of bacterial cholangitis. If PSC presents with fever, however, the complication of bacterial cholangitis should be suspected. According to Olsson et al., ${ }^{3}$ fever was observed in $15 \%$ of PSC patients and in $50 \%$ of those whose bile duct lesion was limited to the intrahepatic bile duct.

In the diagnosis of PSC, the following diagnostic criteria, proposed by La Russo et al., ${ }^{4}$ are often used, except for cholelith, post-biliary operation cholangitis and secondary sclerosing cholangitis caused by biliary tract tumor.

(1) Increase in the serum alkaline phosphatase level of two times or more than the normal level (however, patients with an increase of less than two times normal account for $35 \%$ of PSC cases in Japan)

(2) Diffuse stricture or bead-like change in the intraand extrahepatic bile ducts 
(3) Histological findings that include fibrosed bile duct, obstructive cholangitis, and disappearance of bile duct

(4) No history of biliary tract operation other than cholecystectomy, and the absence of cholelith

The diagnostic criteria proposed by the Mayo Clinic group in $1994^{5}$ attach the greatest importance to cholangiographic findings, such as beaded appearance, band-like stricture, and diverticulum-like outpouching, and this group argues that the diagnosis of PSC only by liver biopsy is difficult. One of the important issues in the diagnosis of PSC is complication by and differentiation from bile duct cancer. As it has been reported that $7.1 \%(5 / 71)$ of the patients who died of PSC had bile duct cancer (cholangiocarcinoma), patients presenting with atypical stricture of the bile duct should undergo histopathological diagnosis with a biopsy, using percutaneous transhepatic cholangiography (PTCS).

\section{Q23. What is the optimal treatment method for localized PSC}

\section{Surgical treatment is effective in some patients with localized PSC (recommendation C). However, be- cause the treatment has been done in few patients, the indication should be carefully chosen.}

It is considered that the prognosis of PSC is poor, because it is associated with obstructive jaundice caused by the progressive sclerosing and stricture of the intraand extrahepatic bile ducts, and ultimately progresses to secondary biliary cirrhosis of the liver and liver failure. However, there are increasing numbers of reports of localized cases. According to a review of reports in Japan, the long-term prognosis of localized PSC is good, and 10 of 12 patients operated on were without recurrence, while all 4 patients not operated died of the disease. This result may indicate good prognosis for localized PSC, if the patients undergo excision of the lesion (level 4). ${ }^{6}$

\section{Conclusion}

The characteristics, diagnostic criteria, treatment guidelines for, and prognoses of specific biliary tract infections have been discussed, and it is hoped that the Guidelines will be useful.

Acknowledgments. We would like to express our deep gratitude to the Japanese Society for Abdominal Emergency Medicine, the Japan Biliary Association, and the Japanese Society of Hepato-Biliary-Pancreatic Surgery, who provided us with great support and guidance in the preparation of the Guidelines. This process was conducted as part of the Project on the Preparation and Diffusion of Guidelines for the Management of Acute Cholangitis (H-15-Medicine-30), with a research subsidy for fiscal 2003 and 2004 (Integrated Research Project for Assessing Medical Technology) sponsored by the Japanese Ministry of Health, Labour, and Welfare.

We also truly appreciate the panelists who cooperated with and contributed significantly to the International Consensus Meeting, held on April 1 and 2, 2006.

\section{References}

\section{Pediatric biliary tract infections}

1. Friesen C, Roberts C. Cholelithiasis: clinical characteristics in children. Clin Pediatr 1989;28:194-298. (level 4)

2. Rescorla FJ. Cholelithiasis, cholecystitis, and common bile duct stones. Current Opin Pediatr 1997;9:276-82. (level 3b)

3. Pokorny WJ, Saleem M, O'Gorman RB. Cholelithiasis and cholecystitis in childhood. Am J Surg 1984;148:742-4. (level 4)

4. Lobe TE. Cholelithiasis and cholecystitis in children. Semin Pediatr Surg 2000;9:170-6. (level 4)

5. Gottrand F, Bernard O, Hadchouel M. Late cholangitis after successful surgical repair of biliary atresia. Am J Dis Child 1991;145:213-15. (level 4)

6. Rothenberg SS, Schroter GP, Karrer FM. Cholangitis after the Kasai operation for biliary atresia. J Pediatr Surg 1989;24:729-32. (level 4)

7. Ecoffey C, Rothman E, Bernard O. Bacterial cholangitis after surgery for biliary atresia. J Pediatr 1987;111:824-9. (level 4)

8. Howard ER. Extrahepatic biliary atresia: a review of current management. Br J Surg 1983;70:193-7. (level 4)

9. Imamoglu M, Serihan H, Sari A, Ahmetoglu A. Acute acalculous cholecystitis in children: diagnosis and treatment. J Pediatr Surg 2002;37:36-9. (level 4)

\section{Geriatric biliary tract infections}

1. Ashton CE, McNabb WR, Wilkinson ML, Lewis RR. Endoscopic retrograde cholangiopancreatography in elderly patients. Age Ageing 1998;27:683-8. (level 4)

2. Mitchell RM, O'Connor F, Dickey W. Endoscopic retrograde cholangiopancreatography is safe and effective in patients 90 years of age and older. J Clin Gastroenterol 2003;36:72-4.

3. Deenitchin GP, Konomi H, Kimura H, Ogawa Y, Naritomi G, Chijiiwa K, et al. Reappraisal of safety of endoscopic sphincterotomy for common bile duct stones in the elderly. Am J Surg 1995;170:51-4. (level 3b)

4. Sugiyama M, Atomi Y. Treatment of acute cholangitis due to choledocholithiasis in elderly and younger patients. Arch Surg 1997;132:1129-33. (level 3b)

5. Akiyama H, Okazaki T, Takashima I, Satoh S, Ryan T, Iwamori $\mathrm{S}$, et al. Percutaneous treatments for biliary diseases. Radiology 1990;176:25-30. (level 4)

6. Tokunaga $\mathrm{Y}$, Nakayama N, Ishikawa $\mathrm{Y}$, Nishitai R, Irie A, Kaganoi J, et al. Surgical risks of acute cholecystitis in elderly. Hepatogastroenterology 1997;44:671-6. (level 3b)

7. Andersson R, Tranberg KG, Bengmark S. Bile peritonitis in acute cholecystitis. HPB Surg 1990;2:7-12; discussion 12-3.

8. Avrahami R, Badani E, Watemberg S, Nudelman I, Deutsch AA, Rabin E, et al. The role of percutaneous transhepatic cholecys- 
tostomy in the management of acute cholecystitis in high-risk patients. Int Surg 1995;80:111-14. (level 4)

9. Davis CA, Landercasper J, Gundersen LH, Lambert PJ. Effective use of percutaneous cholecystostomy in high-risk surgical patients: techniques, tube management, and results. Arch Surg 1999;134:727-31; discussion 731-2. (level 4)

10. Lee KT, Wong SR, Cheng JS, Ker CG, Sheen PC, Liu YE. Ultrasound-guided percutaneous cholecystostomy as an initial treatment for acute cholecystitis in elderly patients. Dig Surg 1998;15:328-32.

11. Edlund G, Ljungdahl M. Acute cholecystitis in the elderly. Am J Surg 1990;159:414-16; discussion 416. (level 3b)

12. Margiotta SJ Jr, Horwitz JR, Willis IH, Wallack MK. Cholecystectomy in the elderly. Am J Surg 1988;156:509-12. (level 4)

13. Borzellino G, de Manzoni G, Ricci F, Castaldini G, Guglielmi A, Cordiano C. Emergency cholecystostomy and subsequent cholecystectomy for acute gallstone cholecystitis in the elderly. Br J Surg 1999;86:1521-5.

14. Chikamori F, Kuniyoshi N, Shibuya S, Takase Y. Early scheduled laparoscopic cholecystectomy following percutaneous transhepatic gallbladder drainage for patients with acute cholecystitis. Surg Endosc 2002;16:1704-7.

15. Pessaux P, Regenet N, Tuech JJ, Rouge C, Bergamaschi R, Arnaud JP. Laparoscopic versus open cholecystectomy: a prospective comparative study in the elderly with acute cholecystitis. Surg Laparosc Endosc Percutan Tech 2001;11:2525.

16. Feldman MG, Russell JC, Lynch JT, Mattie A. Comparison of mortality rates for open and closed cholecystectomy in the elderly: connecticut statewide survey. J Laparoendosc Surg 1994;4:16572. (level 4)

17. Massie MT, Massie LB, Marrangoni AG, D'Amico FJ, Sell HW Jr. Advantages of laparoscopic cholecystectomy in the elderly and in patients with high ASA classifications. J Laparoendosc Surg 1993;3:467-76. (level 3b)

18. Chau CH, Tang CN, Siu WT, Ha JP, Li MK. Laparoscopic cholecystectomy versus open cholecystectomy in elderly patients with acute cholecystitis: retrospective study. Hong Kong Med J 2002;8:394-9. (level 3b)

19. Uecker J, Adams M, Skipper K, Dunn E. Cholecystitis in the octogenarian: is laparoscopic cholecystectomy the best approach? Am Surg 2001;67:637-40. (level 3b)

20. Magnuson TH, Ratner LE, Zenilman ME, Bender JS. Laparoscopic cholecystectomy, applicability in the geriatric population. Am Surg 1997;63:91-6. (level 3b)

\section{Acalculous cholecystitis}

1. Kang JY, Williamson RC. Cholecystitis without gallstones. HPB Surg 1990;2:83-103. (level 4)

2. Glenn F, Becker CG. Acute acalculous cholecystitis. An increasing entity. Ann Surg 1982;195:131-6. (level 2c)

3. Fox MS, Wilk PJ, Weissmann HS, Freeman LM, Gliedman M. Acute acalculous cholecystitis. Surg Gynecol Obstet 1984;159:1316. (level 4)

4. Johnson LB. The importance of early diagnosis of acute acalculous cholecystitis. Surg Gynecol Obstet 1987;164:197-203. (level 4)

5. Ryu JK, Ryu KH, Kim KH. Clinical features of acute acalculous cholecystitis. J Clin Gastroenterol 2003;36:166-9. (level 4)

6. Kalliafas S, Ziegler DW, Flancbaum L, Choban PS. Acute acalculous cholecystitis: incidence, risk factors, diagnosis, and outcome. Am Surg 1998;64:471-5. (level 4)

7. Ryu JK, Ryu KH, Kim KH. Clinical features of acute acalculous cholecystitis. J Clin Gastroenterol 2003;36:166-9. (level 4)

8. Ida T, Morimoto T, Tarumi T, Yamato T, Hisano S, Nakagawa $\mathrm{M}$, et al. Current status of benign biliary disorders in Japan and accuracy rates of preoperative diagnoses. Collective review of 14654 patients. Am J Surg 1983;146:269-73. (level 4)

9. Berger H, Pratschke E, Arbogast H, Stabler A. Percutaneous cholecystostomy in acute acalculous cholecystitis. Hepatogastroenterology 1989;36:346-8. (level 4)

10. Shaked G, Ovnat A, Eyal A, Fraser D, Klain J, Peiser J, et al. Acute acalculous cholecystitis - experimental and clinical observations. Isr J Med Sci 1988;24:401-4. (level 4)

11. Scher KS, Sarap MD, Jaggers RL. Acute acalculous cholecystitis complicating aortic aneurysm repair. Surg Gynecol Obstet 1986;163:475-8. (level 4)

12. Ouriel K, Green RM, Ricotta JJ, DeWeese JA, Adams JT. Acute acalculous cholecystitis complicating abdominal aortic aneurysm resection. J Vasc Surg 1984;1:646-8. (level 4)

13. Hagino RT, Valentine RJ, Clagett GP. Acalculous cholecystitis after aortic reconstruction. J Am Coll Surg 1997;184:245-8. (level 4)

14. Leitman IM, Paull DE, Barie PS, Isom OW, Shires GT. Intraabdominal complications of cardiopulmonary bypass operations. Surg Gynecol Obstet 1987;165:251-4. (level 4)

15. Barie PS. Acalculous and postoperative cholecystitis. In: Barie PS, Shires GT, editors. Surgical intensive care. Boston: Little Brown 1993. p. 837-57. (level 4)

16. Sessions SC, ScoS, Sheikh FA, McGeehin WH, Smink RD Jr. Acute acalculous cholecystitis following open heart surgery. Am Surg 1993;59:74-7. (level 4)

17. Savino JA, Scalea TM, Del Guercio LR. Factors encouraging laparotomy in acalculous cholecystitis. Crit Care Med 1985;13:37780. (level 4)

18. Welling RE, Rath R, Albers JE, Glaser RS. Gastrointestinal complications after cardiac surgery. Arch Surg 1986;121:1178-80. (level 4)

19. Barie PS, Fischer E. Acute acalculous cholecystitis. J Am Coll Surg 1995;180:232-44. (level 4)

20. Steed DL, Brown B, Reilly JJ, Peitzman AB, Griffith BP, Hardesty RL, et al. General surgical complications in heart and heart-lung transplantation. Surgery 1985;98:739-45. (level 4)

21. Merrell SW, Ames SA, Nelson EW, Renlund DG, Karwande SV, Burton NA, et al. Major abdominal complications following cardiac transplantation. Utah Transplantation Affiliated Hospitals Cardiac Transplantation Progra Surg 1989;124:889-94. (level 4)

22. Rakhit A, Nurko S, Gauvreau K, Mayer JE, Blume ED. Gastrointestinal complications after pediatric cardiac transplantation. J Heart Lung Transplant 2002;21:751-9. (level 4)

23. Inoue T, Mishima Y. Postoperative acute cholangitis: a collective review of 494 cases in Japan. Jpn J Surg 1988;18:35-42. (level 4)

24. Raunest J, Imhof M, Rauen U, Ohmann C, Thon KP, Burrig KF. Acute cholecystitis: a complication in severely injured intensive care patients. J Trauma 1992;32:433-40. (level 4)

25. Pitt HA, King W 3rd, Mann LL, Roslyn JJ, Berquist WE, Ament $\mathrm{ME}$, et al. Increased risk of cholelithiasis with prolonged total parenteral nutrition. Am J Surg 1983;145:106-12. (level 4)

26. Petersen SR, Sheldon GF. Acute acalculous cholecystitis: a complication of hyperalimentation. Am J Surg 1979;138:814-17.

27. Andry G, Turnbull AD, Botet J, Kurtz RC. Cholesonographic characteristics of cystic duct metastasis causing acute acalculous cholecystitis: case report. J Surg Oncol 1986;31:178-81. (level 4)

28. Barnett KT, Malafa MP. Complications of hepatic artery infusion: a review of 4580 reported cases. Int J Gastrointest Cancer 2001;30:147-60. (level 4)

29. Lafon PC, Reed K, Rosenthal D. Acute cholecystitis associated with hepatic arterial infusion of floxuridine. Am J Surg 1985; 150:687-9. (level 4)

30. Papaioannou CC, Hunder GG, Lie JT. Vasculitis of the gallbladder in a 70 -year-old man with giant cell (temporal) arteritis. J Rheumatol 1979;6:71-6. (level 4)

31. Smith JP, Bodai BI. Empyema of the gallbladder - potential consequence of medical intensive care. Crit Care Med 1982;10:4512. (level 4) 
32. Shpitz B, Sigal A, Kaufman Z, Dinbar A. Acute cholecystitis in diabetic patients. Am Surg 1995;61:964-7. (level 2b)

33. Landau O, Deutsch AA, Kott I, Rivlin E, Reiss R. The risk of cholecystectomy for acute cholecystitis in diabetic patients. Hepatogastroenterology 1992;39:437-8. (level 2c)

34. Chung-Park M, Kim B, Molya G, Karlins N, Wojcik E. Acalculous lymphoeosinophilic cholecystitis associated with interleukin2 and lymphokine-activated killer cell therapy. Arch Pathol Lab Med 1990;114:1073-5. (level 4)

35. Wiboltt KS, Jeffrey RB Jr. Acalculous cholecystitis in patients undergoing bone marrow transplantation. Eur J Surg 1997;163:51924. (level 4)

36. Hiatt JR, Kobayashi MR, Doty JE, Ramming KP. Acalculous candida cholecystitis: a complication of critical surgical illness. Am Surg 1991;57:825-9. (level 4)

37. Monno S, Mizushima Y. Leptospirosis with acute acalculous cholecystitis and pancreatitis. J Clin Gastroenterol 1993;16:52-4. (level 4)

38. Yulevich A, Cohen Z, Maor E, Bryk T, Mares AJ. Acute acalculous cholecystitis caused by Salmonella typhi in a 6-year-old child. Eur J Pediatr Surg 1992;2:301-3. (level 4)

39. Winkler AP, Gleich S. Acute acalculous cholecystitis caused by Salmonella typhi in an 11-year-old. Pediatr Infect Dis J 1988;7:1258. (level 4)

40. Lillemoe KD, Pitt HA, Kaufman SL, Cameron JL. Acute cholecystitis occurring as a complication of percutaneous transhepatic drainage. Surg Gynecol Obstet 1989;168:348-52. (level 4)

41. Cello JP. AIDS-Related biliary tract disease. Gastrointest Endosc Clin N Am 1998;8:963. (level 4)

42. LaRaja RD, Rothenberg RE, Odom JW, Mueller SC. The incidence of intra-abdominal surgery in acquired immunodeficiency syndrome: a statistical review of 904 patients. Surgery 1989;105(2 Pt 1):175-9. (level 4)

43. Takahashi T, Yamamura T, Utsunomiya J. Pathogenesis of acute cholecystitis after gastrectomy. Br J Surg 1990;77:536-9. (level 4)

44. Saito A, Shirai Y, Ohzeki H, Hayashi J, Eguchi S. Acute acalculous cholecystitis after cardiovascular surgery. Surg Today 1997;27:907-9. (level 4)

45. Ishikawa S, Ohtaki A, Koyano T, Takahashi T, Sato Y, Nakamura $\mathrm{S}$, et al. Percutaneous transhepatic gallbladder drainage for acute acalculous cholecystitis following cardiovascular surgery. J Cardiovasc Surg (Torino) 1997;38:513-15. (level 4)

46. Inoue T, Mishima Y. Postoperative acute cholecystitis: a collective review of 494 cases in Japan. Jpn J Surg 1988;18:35-42. (level 4)

47. Kang JY, Williamson RC. Cholecystitis without gallstones. HPB Surgery 1990;2:83-103. (level 5)

48. Babb RR. Acute acalculous cholecystitis. J Clin Gastroenterol 1992;15:238-41. (level 4)

49. Lillemoe KD. Surgical treatment of biliary tract infections. Am Surgeon 2000;66:138-44. (level 4)

50. Mariat G, Mahul P, Prev t N, De Filippis JP, Cuilleron M, Dubois F, et al. Contribution of ultrasonography and cholescintigraphy to the diagnosis of acute acalculous cholecystitis in intensive care unit patients. Intensive Care Med 2000;26:1658-63. (level 4)

51. Jeffrey RB Jr, Sommer FG. Follow-up sonography in suspected acalculous cholecystitis: preliminary clinical experience. J Ultrasound Med 1993;12:183-7. (level 4)

52. Helbich TH, Mallek R, Madl C, Wunderbaldinger P, Breitenseher M, Tscholakoff D, et al. Sonomorphology of the gallbladder in critically ill patients. Value of a scoring system and follow-up examinations. Acta Radiol 1997;38:129-34. (level 4)

53. Shapiro MJ, Luchtefeld WB, Kurzweil S, Kaminski DL, Durham RM, Mazuski JE. Acute acalculous cholecystitis in the critically ill. Am Surgeon 1994;60:335-9 (level 4)

54. Barie PS, Fischer E. Acute acalculous cholecystitis. J Am Coll Surg 1995;180:232-44 (level 4)
55. Frazee RC, Nagorney DM, Mucha P Jr. Acute acalculous cholecystitis. Mayo Clin Proc 1989;64:163-7. (level 4)

56. Sugiyama M, Tokuhara M, Atomi Y. Is percutaneous cholecystostomy the optimal treatment for acute cholecystitis in the very elderly? World J Surg 1998;22:459-63. (level 4)

\section{Acute and intrahepatic segmental cholangitis associated with hepatolithiasis}

1. Kim MH, Sikijima J, Lee SP. Primary intrahepatic stones. Am J Gastroenterol 1995;90:540-8.

2. Uchiyama K, Tanimura H. Oriental cholangiohepatitis. Jpn J Clin Med-Medical Syndrome of Hepato-Biliary Tract Disease 1995;7: 134-6. (level 4)

3. Hamaloglu E. Biliary ascariasis in 15 patients. Int Surg 1992;77:779. (level 4)

4. Sasaki M, Nakanuma Y, Kim YS. Expression of apomucins in the intrahepatic biliary tree in hepatolithiasis differs from that in normal liver and extrahepatic biliary obstruction. Hepatology 1998;27:54-61.

5. Furukawa M, Sasaki M, Ohtubo M, et al. Natural history of primary hepatolithiasis. J Biliary Tract Pancreas 1998;19:1021-7. (level 4)

6. Ohta T, Nagakawa T, Konishi I, Ueno K. Clinical experience of intrahepatic cholangiocarcinoma associated with hepatolithiasis. Jpn J Surg 1988;18:47-53. (level 4)

7. Chen MF, Jan YY, Wang CS, Jeng LB, Hwang TL, Chen SC. Intrahepatic stones associated with cholangiocarcinoma. Am J Gastroenterol 1989;84:391-5. (level 4)

8. Liu CL, Fan ST, Wong J. Primary biliary stones: diagnosis and management. World J Surg 1998;22:1162-6. (level 4)

9. Nakanuma Y, Harada K, Ishikawa A, Zen Y, Sasaki M. Anatomic and molecular pathology of intrahepatic cholangiocarcinoma. J Hepatobiliary Pancreat Surg 2003;10:265-81.

10. Rella JG, Shamamian P, Chiang W. Recurrent pyogenic cholangitis. Acad Emerg Med 1997;4:1173-6. (level 4)

11. Van Sonnenberg E, Casola G, Cubberley DA. Oriental cholangiohepatitis: diagnostic imaging and interventional management. AJR Am J Roentgenol 1986;146:327-31. (level 4)

12. Chan FL, Man SW, Leong LLY, Fan ST. Evaluation of recurrent pyogenic cholangitis with CT: analysis of 50 patients. Radiology 1989;170:165-9. (level 4)

13. Lim JH. Oriental cholangiohepatitis: pathologic, clinical, and radiologic features. AJR Am J Roentgenol 1991;157:1-8. (level 4)

\section{Acute biliary tract infections associated with malignant pancreatic-biliary cancer}

1. Sohn TA, Yeo CJ, Cameron JL, Pitt HA, Lillemoe KD. Do preoperative biliary stents increase postpancreaticoduodenectomy complications? J Gastrointest Surg 2000;4:258-67. (level 4)

2. Ten Hoopen-Neumann H, Gerhards MF, van Gulik TM, Bosma A, Verbeek PC, Gouma DJ. Occurrence of implantation metastases after resection of Klatskin tumors. Dig Surg 1999;16:209-13. (level 4)

\section{Postoperative biliary tract infections}

1. Bergman JJ, Rauws EA, Fockens P, van Berkel AM, Bossuyt PM, Tijssen JG, et al. Randomised trial of endoscopic balloon dilation versus endoscopic sphincterotomy for removal of bile duct stones. Lancet 1997;349:1124-9. (level 4) 
H. Yasuda et al.: Tokyo Guidelines for unusual cases of acute cholangitis and cholecystitis

2. Ramirez P, Parrilla P, Bueno FS, Abad JM, Muelas MS, Candel $\mathrm{MF}$, et al. Choledochoduodenostomy and sphincterotomy in the treatment of choledocholithiasis. Br J Surg 1994;81:121-3. (level 4)

3. Henri B, Dominique F, Marvin BC, Jacques H. Long term result of Roux-en-Y hepaticojejunostomy. Surg Gynecol Obstet 1978; 146:161-7. (level 4)

4. McKee JD, Raju GP, Edelman RR, Levine H, Steer M, Chuttani R. MR cholangio-pancreatography (MRCP) in diagnosis of afferent loop syndrome presenting as cholangitis. Dig Dis Sci 1997;42:2082-6. (level 4)

5. Miros M, Kerlin P, Strong R, Hartley L, Dickey D. Postcholedochoenterostomy "sump syndrome". Austr NZ J Surg 1990;60:109-12. (level 4)

6. Panis Y, Fagniez P-L, Brisset D, Lacaine F, Levard H, Hay JM. Long term results of choledochoduodenostomy versus choledochojejunostomy for choledocholithiasis. The French Association for Surgical Research. Surg Gynecol Obstet 1993;177:33-7. (level 4)

7. Livraghi T, Goldberg SN, Lazzaroni S, Meloni F, Solbiati L, Gazelle GS. Small hepatocellular carcinoma: treatment with radio-frequency ablation versus ethanol injection. Radiology 1999;210:655-61. (level 4)

8. Riley DK, Babinchak TJ, Zemel R, Weaver ML, Rotheram EB. Infectious complications of hepatic cryosurgery. Clin Infecti Dis 1997;24:1001-3.

9. Ito T. Acute noncalculous cholecystitis following gastrectomy for gastric cancer. Study by ultrasonic examination. J Jpn Surg Soc 1985;86:1434-43. (level 4)

\section{Acute biliary tract infection associated with congenital biliary dilatation}

1. Matsumoto Y, Fujii H, Itakura J, et al. Clinical aspects of pancreaticobiliary maljunction. In: Koyanagi Y, Aoki T, editors. Pancreaticobiliary maljunction. Tokyo: Igaku Tosho Shuppan; 2002. p. 125-31. (level 4)
2. Egami K, Tajiri T, Uchida E, et al. Pancreaticobiliary maljunction: Its etiological role in biliary disease. In: Koyanagi Y, Aoki T, editors. Pancreaticobiliary maljunction. Tokyo: Igaku Tosho Shuppan; 2002. p. 197-208. (level 4)

3. Rha SY, Stovroff MC, Glick PL, et al. Choledochal cysts: a 10-year experience. Am Surg 1996;62:30-4. (level 4)

4. Takamatsu H, Noguchi H, Tahara H, et al. Childhood manifestations of congenital biliary dilatation (choledochal cyst). In: Koyanagi Y, Aoki T, editors. Pancreaticobiliary maljunction. Tokyo: Igaku Tosho Shuppan; 2002. p. 103-9. (level 4)

5. Kaneko K, Ando H, Seo T. Intrahepatic calculi after bile duct excision for pancreaticobiliary maljunction. In: Koyanagi Y, Aoki T, editors. Pancreaticobiliary maljunction. Tokyo: Igaku Tosho Shuppan; 2002. p. 375-82. (level 4)

\section{Primary sclerosing cholangitis}

1. Takikawa H, Takamori Y, Tanaka A, Kurihara H, Nakanuma Y. Analysis of 388 cases of primary sclerosing cholangitis in Japan. Presence of a subgroup without pancreatic involvement in older patients. Hepatol Res 2004;29:153-9. (level 4)

2. Nakanuma Y, Harada K, Katayanagi K, et al. Definition and pathology of primary sclerosing cholangitis. J Hepatobiliary Pancreat Surg 1999;6:333-42.

3. Olsson R, Danielsson A, Jarnerot G, et al. Prevalence of primary sclerosing cholangitis in patients with ulcerative colitis. Gastroenterology 1991;100:1319-23.

4. Craig DA, MacCarty RL, Wiesner RH, Grambsch PM, LaRusso NF. Primary sclerosing cholangitis: value of cholangiography in determining the prognosis. AJR Am J Roentgenol 1991;157:95964. (level 4)

5. Weisner RH. Current concepts in primary sclerosing cholangitis. Mayo Clin Proc 1994;69:969-82.

6. Cameron JL, Pitt HA, Zinner MJ, Herlong HF, Kaufman SL, Boitnott JK, et al. Resection of hepatic duct bifurcation and transhepatic stenting for sclerosing cholangitis. Ann Surg 1988;207:61422. (level 4) 